Revista Destaques Acadêmicos, Lajeado, v. 11, n. 4, 2019. ISSN 2176-3070

DOI: http://dx.doi.org/10.22410/issn.2176-3070.v11i4a2019.2242

http://www.univates.br/revistas

\title{
O JOGO DA VELHA SOBRE MECÂNICA: RELATO DE EXPERIÊNCIA
}

\author{
Bruce Willys da Silva Moreira' ${ }^{1}$, Paulo Cesar Alves Contreiras Junior ${ }^{1}$, \\ Suziane Lima do Nascimento ${ }^{1}$, Bianca Martins Santos ${ }^{2}$, \\ Marcos Whisley Viana Nobree ${ }^{3}$
}

\begin{abstract}
Resumo: O presente estudo tem por objetivo apresentar uma proposta de ensino, baseada em uma gincana de jogo da velha; bem como relatar os resultados sobre a aplicação desta metodologia à uma turma de primeiro ano de ensino médio, em uma escola pública de Rio Branco / AC. A aula foi elaborada e aplicada por graduandos que participam do programa de Iniciação à Docência do curso de licenciatura em física da Universidade Federal do Acre. A sequência didática de ensino envolveu quatro encontros, com duração de uma hora cada. Nas três primeiras aulas foram revisados os assuntos: Leis de Newton, Trabalho e Energia, respectivamente. E na quarta aula, foi aplicado uma gincana a partir de duelos de jogo da velha entre as equipes. Para a competição, os alunos foram divididos em oito grupos de três ou quatro alunos. De duas em duas equipes, foram estabelecidas as disputas. Em forma de torneio, as equipes que perdessem as disputas eram eliminadas, até sobrar a equipe vencedora. Quanto aos resultados observados, a proposta mostrou-se proveitosa para os estudantes, bem como para os futuros professores, que experienciaram a docência ainda durante sua formação inicial.
\end{abstract}

Palavras-chave: Ensino de física; Mecânica; Gincana; Jogo da velha.

1 Discentes do Curso de Licenciatura em Física da Universidade Federal do Acre (UFAC) e bolsistas do Programa Institucional de Bolsa de Iniciação à Docência (PIBID).

2 Licenciatura em Física na Universidade Federal Rural do Rio de Janeiro (UFRRJ), Mestrado em Engenharia Nuclear no Instituto Militar de Engenharia (IME), Doutorado em Física na Universidade Federal Fluminense (UFF). Docente de Física da Universidade Federal do Acre (UFAC), Coordenadora do Mestrado Nacional Profissional em Ensino de Física (MNPEF) - Polo 59 e Coordenadora do Programa de Institucional de Bolsas de Iniciação à Docência (PIBID) da UFAC - Subprojeto de Física.

3 Licenciatura em Física na Universidade Federal do Acre (UFAC). Docente pela Secretaria do Estado de Educação - Acre (SEE/AC) 


\section{INTRODUÇÃO}

O Programa Institucional de Bolsa de Iniciação à Docência (PIBID), financiado com recursos da Capes - Coordenação de Aperfeiçoamento de Pessoal de Nível Superior, representa uma política pública de incentivo à formação de professores (SILVA e NUNES, 2016). Neste contexto, em particular para o núcleo de trabalho do PIBID do curso de Licenciatura em Física da Universidade Federal do Acre (UFAC), destacam-se os benefícios que o mesmo oferece aos graduandos ainda em formação (SANTOS et al, 2018), pois além de evitar a evasão estudantil dos alunos da licenciatura na universidade, a bolsa concedida pelo programa aos acadêmicos participantes também auxilia na renda familiar de cada discente da modalidade de bolsista remunerado. Por outro lado, o programa permite a vinculação de bolsistas voluntários, e para estes alunos o estímulo financeiro não é concedido. Embora existam desafios a serem superados ao longo da vigência do programa, como acesso às escolas, tendo em vista que algumas são localizadas na zona rural de Rio Branco; a conciliação entre as atividades do programa e as atividades acadêmicas; a dificuldade para construção de recursos didáticos inovadores, segundo o fator financeiro; entre outros, têm-se observado que o PIBID ajuda os futuros docentes à vivenciarem a prática docente em um ambiente real de sala, acompanhando de perto o papel do professor de ensino básico (DARROZ, ROSA e NETO, 2018).

Neste contexto, ressalta-se a importância da participação dos graduandos no programa, devido à dificuldade que estes apresentam para se expressarem, ou até mesmo entrarem em pânico com medo de falar em público (OLIVEIRA, 2017). Em particular o presente trabalho relata uma experiência didática desenvolvida por três alunos do PIBID, onde um dos pibidianos que desenvolveram a ação tinha muita dificuldade para se expressar em público. Outro fato importante a ser mencionado, refere-se à contribuição do programa para melhorar a qualidade do ensino básico, bem como fortalecer a formação inicial dos professores (NASCIMENTO e ANTUNES, 2015).

Para a componente curricular de física, de forma específica, destacase a importância de uma boa formação inicial de professores, pois o nível de complexidade e abstração necessária para compreender os conteúdos é grande. Fato evidenciado por boa parte dos estudantes do ensino médio, pois alguns educandos não compreende os assuntos trabalhados logo no primeiro contato com a matéria. Além disso, este primeiro contato dos alunos da educação básica com a física, que acontece normalmente no primeiro ano do ensino médio, geralmente é marcado por dificuldades de interpretação de texto, falta de domínio com os cálculos matemáticos, entre outros (JUNIOR et al, 2017). Tais dificuldades podem estar associadas ao fato da física se tratar de uma matéria nova e distante do que já foi estudado durante o ensino fundamental, acrescidos dos desafios de compreensão da linguagem matemática exigida na disciplina (PIETROCOLA, 2002). 
Em geral, o ensino de física para o nível médio pode resumir-se apenas na decoreba das fórmulas físicas e técnicas de resolução de exercícios. Neste ponto, vale destacar o que afirma Carvalho e Pérez (2009) sobre este tema,

\begin{abstract}
[...] verifica-se, com efeito, que os "problemas" são explicados como algo que se sabe fazer, como algo cuja a solução se conhece e que não gera dúvidas, nem exige tentativas: o professor conhece a situação - para ele não é um problema - e a explica linearmente, "com toda clareza". Em consequência, os alunos podem aprender essa solução e repeti-la ante situações idênticas, sem contudo aprender a abordar um verdadeiro problema e qualquer pequena mudança já lhes gera dificuldades insuperáveis, provocando o abandono do exercício. (CARVALHO e PÉREZ, 2009, p. 94-95)
\end{abstract}

Outro fator fundamental que está presente nas realidade das salas de aulas de física brasileiras, vai de encontro com à triste realidade de como a educação é tratada no Brasil, "Os professores passam quase a totalidade de seu tempo de trabalho remunerado dentro de salas de aula, lecionando para várias turmas, estas que são no geral bastante populosas" (PUGLIESE, 2017, p. 973). Neste aspecto, quando o professor está sobrecarregado com muitas turmas, e como um número elevado de alunos por classe, não sobra tempo para o docente preparar aulas diferenciadas ou de melhor qualidade para os alunos, um problema grave ligado a uma questão estrutural de como a educação básica está organizada. Este é apenas um dos desafios para o professor de física, de muitos que podem ser citados (MOREIRA, 2018).

Na busca de formar futuros professores, conscientes e preocupados com o aprendizados dos alunos, o PIBID desenvolve trabalhos com as escolas parceiras. Como por exemplo, a proposta de praticar de forma dinâmica e criativa a abordagem ou revisão dos conteúdos de física. Ou investigar meios ou formas de ensinar física, pelos quais os alunos do ensino básico tenham maior afinidade com a disciplina durante o ensino médio. Com este objetivo, o trabalho relata a aplicação de uma dinâmica em sala de aula, durante as ações do PIBID, realizadas no contraturno das aulas regulares. Na oportunidade, uma revisão sobre mecânica foi utilizada, a qual serviu para ajudar aos alunos a terem uma boa noção do que seria cobrado nas avaliações regulares da disciplina de física. De forma dinâmica, competitiva e inusitada, foi aplicado em sala de aula uma dinâmica (gincana) baseada num jogo bem antigo, conhecido como jogo da velha, e renomeado aqui como jogo da velha sobre mecânica.

Essa proposta teve como principal objetivo possibilitar aos alunos da escola a discussão sobre o conteúdo entre os pares (aluno-aluno), bem como fornecer meios que facilitasse a aprendizagem dos conteúdos abordados, neste caso, no ambiente descontraído vivenciado na gincana. Nesta proposta de ensino, os pibidianos pretenderam trazer uma metodologia diferenciada e 
atrativa para revisar o conteúdo com os discentes, bem como experienciar a docência.

\section{METODOLOGIA}

O trabalho apresenta o relato de experiência sobre a aplicação de intervenção didática sobre o conteúdo de Leis de Newton, Trabalho e Energia. O público alvo foram discentes de $1^{\circ}$ ano do Ensino Médio de uma escola pública de Rio Branco / AC. A metodologia de ensino desenvolvida na aula foi elaborada e aplicada por bolsistas do PIBID da UFAC. A presente ação foi realizada durante o contraturno das aulas regulares da escola, como parte das práticas desenvolvidas pelos pibidianos na escola. Vale ressaltar que a escola possui duas turmas de $1^{\circ}$ ano, e no contraturno ambas as turmas frequentavam as aulas promovidas pelos pibidianos em horários diferentes.

A proposta de ensino envolveu quatro aulas com duração de uma hora corrida cada. Nas três primeiras aulas foram trabalhados os assuntos: Leis de Newton, Trabalho e Energia, respectivamente, a partir da revisão do conteúdo e resolução de exercícios do livro didático utilizado na escola (BONJORNO et al, 2016). Para a preparação das aulas, os graduandos utilizaram outras referências (MENEZES et al, 1998; HALLIDAY, RESNICK e WALKER, 2016), mas com a turma adotou-se o livro admitido pela escola. Na quarta aula foi aplicado uma gincana a partir do jogo da velha. Para a competição, os alunos que foram divididos em oito equipes, de três ou quatro alunos em cada grupo. A cada duas equipes foram estabelecidas disputa de jogo da velha adaptado, conforme a Figura 1.

Figura 1: Layout do jogo da velha adaptado para a gincana.

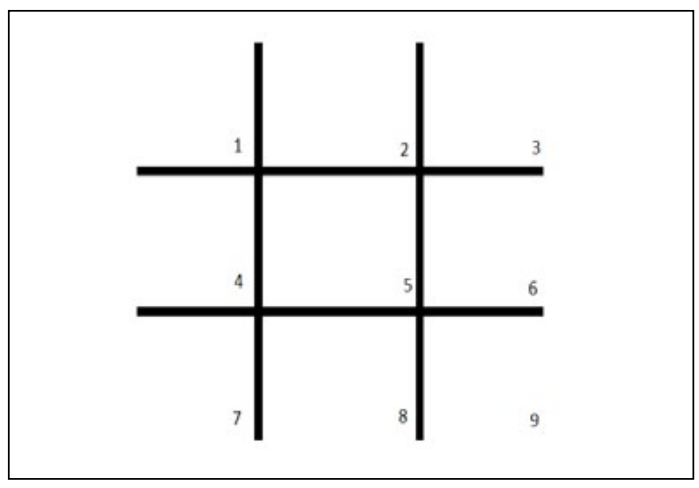

Fonte: Próprio autor.

Iniciaria a partida, o grupo que ganhasse no par ou ímpar. As regras do jogo da velha permaneciam as convencionais, com objetivo de cada grupo, alternando as jogadas, marcar " $\mathrm{X}$ " ou " $\mathrm{O}$ " nos espaços entre as grades da 
Figura 1. A equipe que fechasse uma reta com três pontos primeiro (na vertical, horizontal ou diagonal), seria o vencedor da partida.

Para aplicação, o jogo da velha tradicional ganhou enumerações nas nove lacunas da Figura 1. Para cada lacuna, havia uma pergunta (veja o Apêndice 1) referente ao conteúdo estudado, o grupo da vez de jogar deveria escolher qual número iria responder, garantindo de preferência a melhor estratégia para vencer o jogo. As quatro primeiras disputas foram acompanhadas por um monitor, com a função de ler as questões e marcar o tempo de 3 min para o grupo responder. Para o acerto, o grupo marcaria o símbolo de " $\mathrm{O}$ " ou " $\mathrm{X}$ " no número escolhido. Ao errar a questão, o outro grupo marcaria seu respectivo símbolo, no número escolhido. Lembrando que cada grupo escolheria um único símbolo. E assim sucessivamente, até que uma equipe vencesse o duelo. Quando o jogo acabasse em "velha", ou seja, nenhuma das equipes conseguiam fazer a reta com três pontos, uma questão extra seria passada para os dois grupos. O grupo que respondesse primeiro e corretamente, seria considerado o vencedor do duelo.

Inicialmente eram oito grupos na disputa. Após uma rodada de jogo, os quatros grupos vencedores realizaram uma nova disputa entre os finalistas. Ao final da segunda rodada, as duas equipes vencedoras disputaram a final (Figura 2). Neste ponto, é importante mencionar que para cada fase existia um grau de dificuldade, crescente conforme o nível da disputa. As questões de cada fase estão apresentadas no Apêndice 1.

Figura 2: Divisão dos grupos e a competição.

\begin{tabular}{|l|l|l|l|}
\cline { 1 - 1 } Equipe 1 & \multirow{2}{*}{ Equipe 2 } & \\
\cline { 1 - 1 } Equipe 2 & & \\
\cline { 1 - 1 } Equipe 3 & \multirow{2}{*}{ Equipe 3 } & \\
\cline { 1 - 1 } Equipe 4 & & \multirow{2}{*}{ Equipe 8 } \\
\cline { 1 - 1 } Equipe 5 & \multirow{2}{*}{ Equipe 6 } & \\
\cline { 1 - 1 } Equipe 6 & & \\
\cline { 1 - 1 } Equipe 7 & \multirow{2}{*}{ Equipe 8 } & \\
\cline { 1 - 1 } Equipe 8 & & & \\
\hline
\end{tabular}

Fonte: Próprio autor. 
Como forma de avaliação da proposta de ensino, após a atividade foi aplicado o questionário apresentado no Quadro 1. Para análise dos resultados, foi realizado um estudo qualitativo. $\mathrm{O}$ estudo qualitativo em ensino tem como principal finalidade fornecer informações não numéricas como forma avaliativa e o pesquisador tem por objetivo fornecer a explicação dinâmica da proposta metodológica utilizada para facilitar a compreensão de um certo conteúdo, preocupando-se com a aprendizagem de um grupo social (GERHARDT e SILVEIRA, 2009).

Quadro 1: Questionário avaliativo ao final da atividade.

\begin{tabular}{|l|}
\hline \multicolumn{1}{|c|}{ Questionário } \\
\hline $\begin{array}{l}\text { 1. O que você achou da metodologia sobre o uso de gincana do jogo da velha? } \\
\text { () Otima () Bom ( ) Regular ( ) Ruim }\end{array}$ \\
$\begin{array}{l}\text { 2. Você achou a experiência válida para aprender ou fixar os conteúdos? } \\
\text { ( ) Sim ( ) Não ( ) Um pouco }\end{array}$ \\
\hline 3. Quais as suas sugestões para melhoria da metodologia aplicada? \\
\hline 4. A atividade ajudou você a revisar os conteúdos para prova? \\
\hline 5. Quais os pontos negativos sobre a metodologia aplicada? \\
\hline
\end{tabular}

Fonte: Próprio autor.

As respostas fornecidas pelos estudantes ao questionário avaliativo foram reunidas e apresentadas na seção seguinte, juntamente como o relato da observação sobre a participação dos alunos na gincana.

\section{RESULTADOS}

A aula proposta, com o uso da gincana do jogo da velha sobre mecânica, foi uma estratégia utilizada com o objetivo de desafiar os estudantes à exercitar o tema estudado. Trabalhando em grupos e por meio das perguntas que apareciam no jogo, os educandos revisaram o assunto de forma prática e divertida, tornando o espaço da sala de aula um ambiente de competição e socialização entre os discentes. Na oportunidade, participaram 24 estudantes da atividade (Figura 3). 
Figura 3: Momentos da competição.

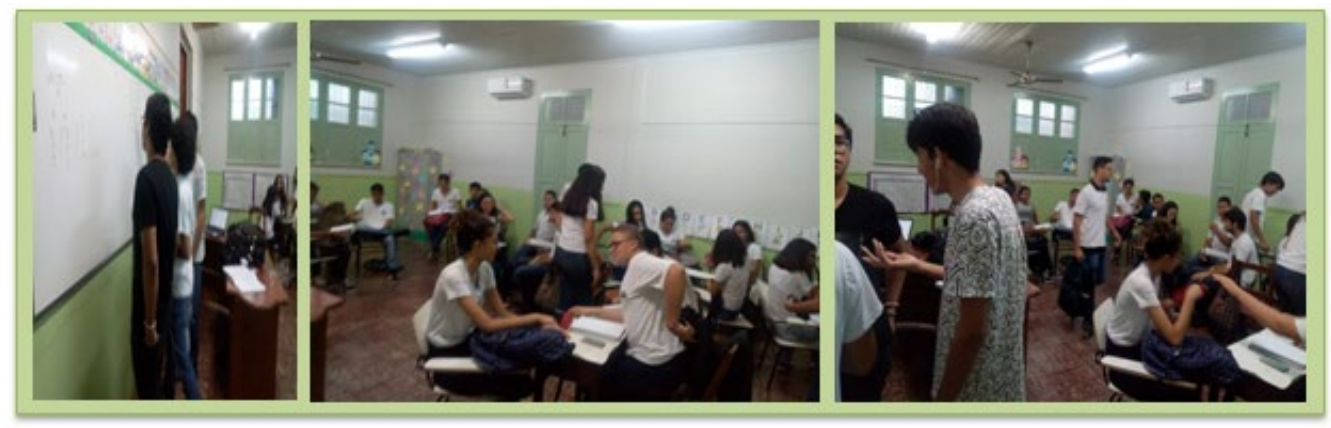

Fonte: Próprio autor.

Como o questionário sobre a atividade foi aplicado em uma aula posterior, só estavam presentes no momento da aplicação do questionário 18 alunos. Portanto, participaram da ação e responderam o questionário o total de 18 alunos, quantidade tomada para composição dos gráficos apresentados a seguir.

Durante a gincana, voltou-se a atenção da turma para as perguntas sobre mecânica, que foram respondidas a maior parte com êxito. Verificou-se também que tal dinâmica (gincana), contribuiu para o trabalho em grupo dos alunos, proporcionando a interação entre os pares para construção do conhecimento, pois os educandos deveriam chegar a um consenso para fornecer a melhor resposta. Fato que tornou a gincana ainda mais interessante.

Neste ponto, vale ressaltar o que Duran (1993, p. 8) afirma sobre a interação social para a construção do conhecimento, que constitui-se

[...] em uma referência ao outro humano, ao indivíduo que não sou eu e que, comigo, divide a cena que me permite, a mim e a ele, agir, e que permite a emergência de realidades às quais o social-sociológico se aplica. Ou seja, o social se configura já a partir da interação social, no mesmo ponto onde o individual se configura e de onde às vezes é recortado para consideração em separado. Do mesmo modo, o cultural também se configura no nível da interação social na medida em que as ações em interdependência são carregadas dos significados cujo compartilhamento, pelos membros da interação, permite-lhes ação articulada [...] (DURAN, 1993, p. 8)

Tal compartilhamento de ideias citado pelo autor, em ação articulada, torna-se necessária para a melhor compreensão de um determinado assunto. Assim, para o caso específico da física, quando trata-se de assuntos complexos ou que exige abstração para o completo entendimento do conceito físico, ou ainda demanda um certo grau de habilidades com as operações matemáticas, a 
interação entre os pares (aluno-aluno) representa um ponto fundamental para a construção do conhecimento.

Além da observação quanto ao comportamento e participação dos alunos na gincana, analisou-se o questionário para verificar o que os alunos acharam da atividade. Sobre a opinião dos alunos quanto à metodologia aplicada, verificou-se que $90 \%$ dos estudantes acharam a atividade boa ou ótima, conforme mostra a Figura 4. Resultado que demonstra ser válido a realização de atividades diferenciadas nas aulas de física, pois além dos discentes demonstrarem aprovação a metodologia proposta, eles podem se envolver e participar com maior empolgação, quando comparada com as aulas apenas expositivas. Quanto à este ponto de investigação, vale mencionar que na literatura existem vários relatos de experiências com atividades envolvendo lúdico e competição, para trabalhar o ensino de diversos temas relacionados à conteúdos de física, onde os autores chegam a conclusões interessantes para tais metodologias, principalmente quanto ao envolvimento dos estudantes nas ações (RODRIGUES et al, 2017; REIS et al, 2018; ARAUJO e SANTOS, 2018).

Figura 4: Resultado do questionário opinário sobre a metodologia, quanto à aprovação do uso.

\section{Opnião dos estudantes sobre a metodologia}

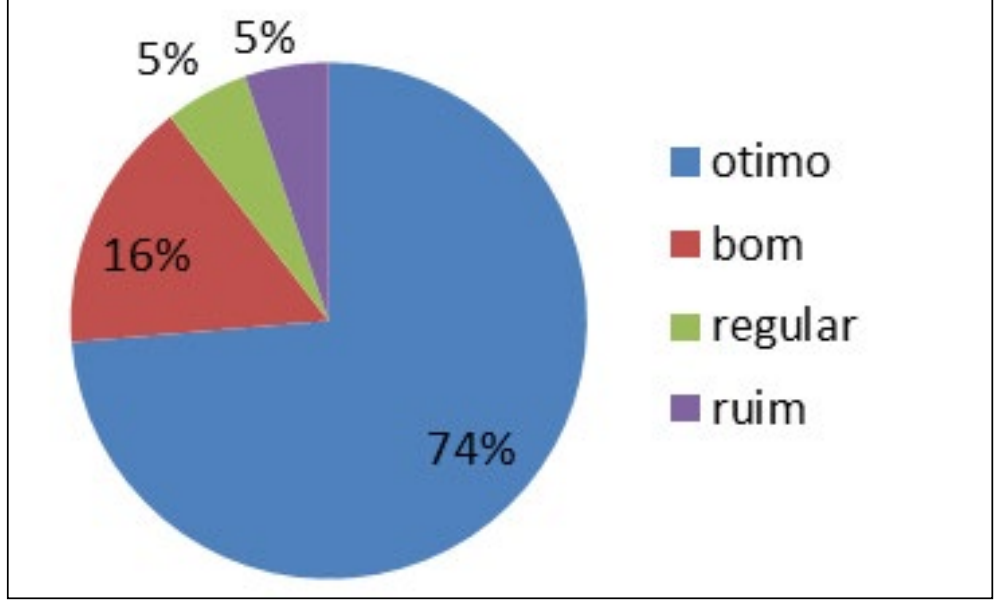

Fonte: Próprio autor

Outro ponto de investigação do questionário foi avaliar se os educandos acharam a experiência válida para aprender ou fixar os conteúdos de mecânica. Na Figura 5 são exibidos resultados que mostram de $72 \%$ acharam que a atividade ajudou, e por outro lado, $22 \%$ apontaram que ajudou pouco para a aprendizagem e $6 \%$ afirmaram que não ajudou. A aprovação da metodologia por grande parte dos educandos, pode está associado ao fato de muitos alunos 
ganharem mais de uma partida e conforme avançavam na gincana, achavam-a interessante e envolviam-se de forma mais participativa, ao mesmo tempo que lembravam os conteúdos cobrados nas questões.

Enquanto que, o percentual de $28 \%$ de reprovação da metodologia pode está relacionado ao desinteresse de poucos alunos, percebidos durante a aplicação da gincana. Ao longo da aplicação da proposta, alguns alunos não estavam empolgados para o jogo e participaram displicentemente, não resolviam as questões de forma consistente, arriscaram qualquer alternativa e não se esforçaram em tentar revisar os conteúdos. Por consequência, não obtiveram um bom aproveitamento na gincana, transparecendo o desentusiasmo, fato que influenciou diretamente o desempenho de tais alunos na revisão dos conteúdos. Neste ponto, vale destacar a importância do aluno ter pré-disposição para aprender (HONORATO, DIAS e DIAS, 2018).

Figura 5: Resultado do questionário opinário sobre a metodologia, quanto à contribuição para a aprendizagem.

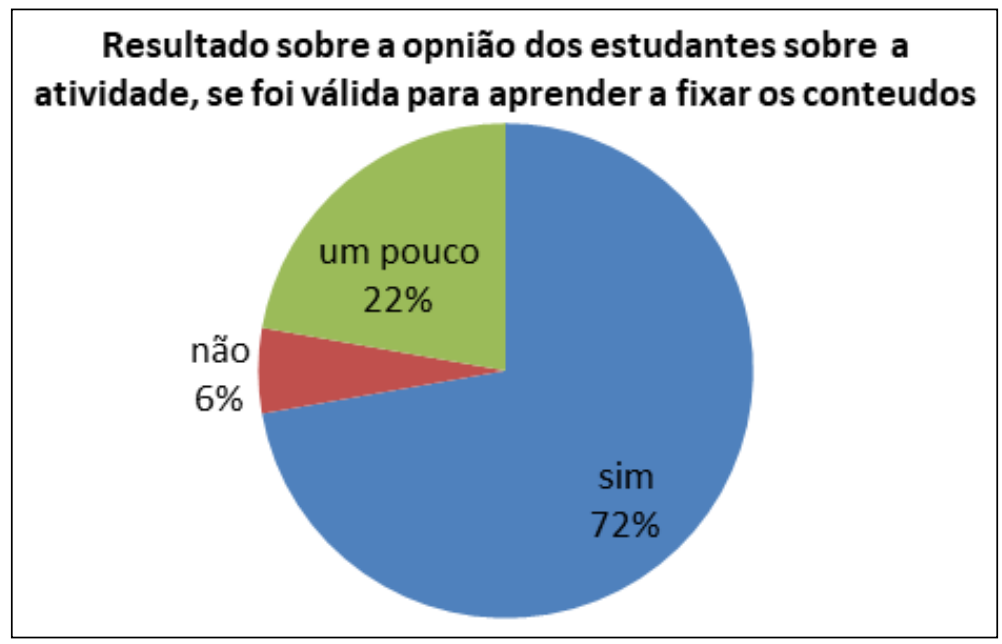

Fonte: Próprio autor

Outro ponto de investigação foi verificar se os educandos teriam sugestões para o aperfeiçoamento da metodologia aplicada, que consistiu da revisão dos temas estudados e aplicação da gincana do jogo da velha. Na Figura 6 são exibidos os resultados que mostram que $22 \%$ dos entrevistados indicaram o interesse por mais aulas interativas, $28 \%$ apontaram a necessidade de maior organização no momento da gincana, $17 \%$ mencionaram o pouco tempo para responder as perguntas e 33\% dos alunos responderam que a não precisava de melhoria. Tais apontamentos dos alunos, principalmente quanto à melhorar a organização e a necessidade de disponibilizar mais tempo para responder as perguntas da gincana, estão de acordo com as afirmações de Pereira, Fusinato 
e Neves (2009) sobre a importância de equilibrar a dinâmica do jogo, entre regras, objetivo e conteúdo trabalhado, para o encaminhamento proveitoso da atividade.

Figura 6: Sugestões dos alunos para melhoria da metodologia aplicada.

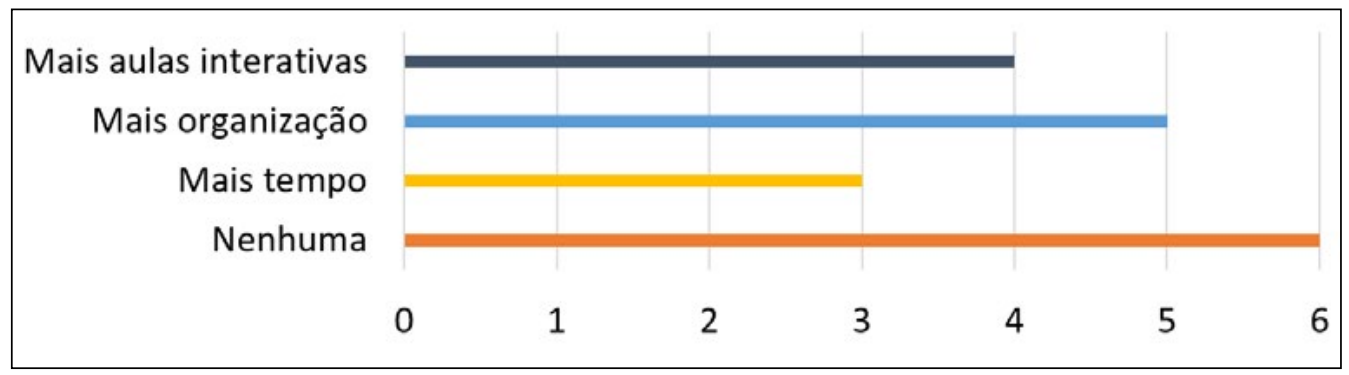

Fonte: Próprio autor

Figura 7: Opinião dos alunos se a atividade ajudou a revisar os conteúdos para prova.

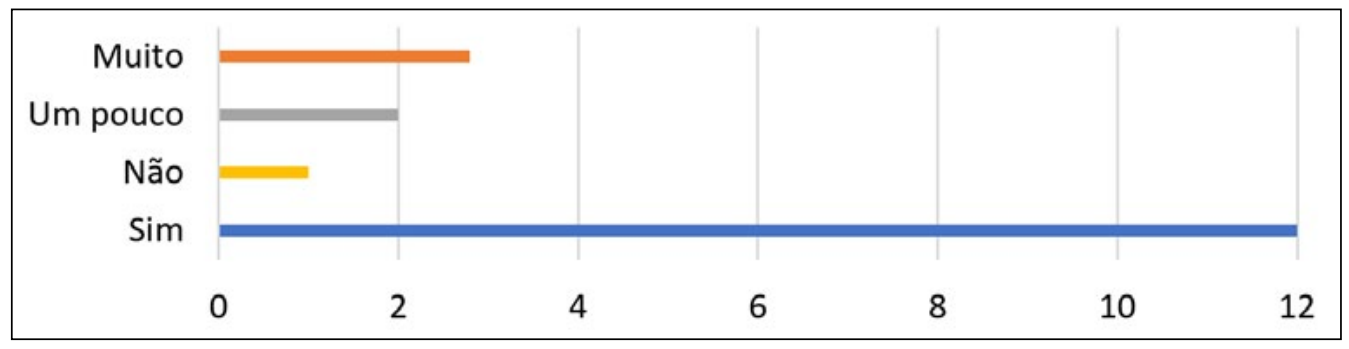

Fonte: Próprio autor

Os resultados da figura 7 mostram qualitativamente o quanto a revisão em forma de gincana auxiliou o grupo de estudantes a obterem uma boa nota em suas avaliações regulares, o gráfico mostra que a grande maioria $(67 \%)$ optou por sim. Nesta perspectiva, Schmitt et al (2011, p. 60) afirmam que durante uma atividade de gincana verifica-se "(...) o interesse dos alunos por situações que os desafiem a pensar e a se superar. Quanto mais desafiadora for a tarefa, geralmente mais empenho os alunos dispendem para realizá-la." Assim, pode-se associar o desafio da gincana ao fato dos alunos terem desenvolvido o interesse em resolver as questões, ação que ajudou na revisão dos conteúdos para prova avaliativa da disciplina.

A figura 8 exibe qualitativamente os pontos negativos da gincana efetuada em sala de aula, onde verificou-se que boa parte dos discentes optaram pelo item nenhum $(40 \%)$. Resultado indicativo de terem poucas dificuldades em participar da atividade. Entretanto, alguns indicaram pontos negativos (o 
total de $61 \%$ ), como muitas pessoas no grupo e pouco tempo para resolver as questões. Esse resultado, enfatiza o que Imbernón (2012, p. 57-58) afirma, no contexto da sala de aula universitária mas que pode ser aplicada ao ensino médio, "Um grupo grande pode impedir a comunicação (...). O ideal seria formar grupos de quatro ou cinco alunos; (...) Trabalhar em grupo requer mais tempo, já que não depende apenas do professor, mas de toda classe."

Figura 8: Resultado do questionário opinário quanto aos pontos negativos sobre a metodologia aplicada.

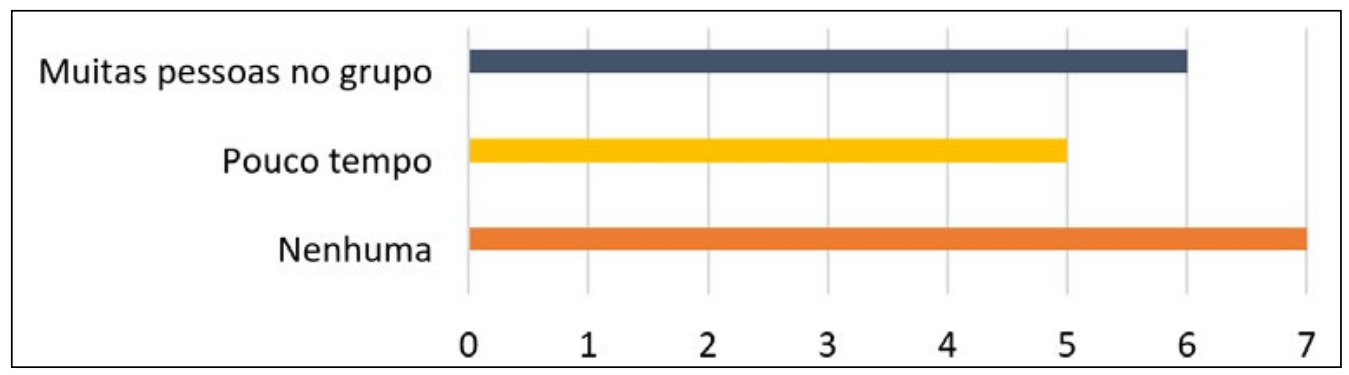

Fonte: Próprio autor

Quanto aos acadêmicos da licenciatura em física da UFAC, percebeu-se que a experiência de docência em sala de aula pode contribuir de forma valiosa para uma melhor formação. Além disso, nos momentos em que os acadêmicos vivenciam a realidade da sala de aula, ainda durante a formação inicial, adquirem experiência sobre as ferramentas de ensino que funcionam, bem como aquelas que não funcionam, além de terem a possibilidade de trabalhar a segurança de falar em público, o domínio de turma, a impostação da voz, a condução de uma aula, entre outros. Fato que diferencia o PIBID de todas as outras ações que ocorrem durante a licenciatura, pois durante o programa o graduando acompanha o trabalho do professor supervisor na escola, propõe ações e as executam. Por estar inserido no ambiente escolar durante boa parte da graduação, esta política pública fornece ao professor em formação possibilidade de conhecer de perto o futuro ambiente de trabalho, dando-lhe condições de uma formação mais completa. Como a ação relatada no trabalho, foi executada durante os primeiros seis meses de participação dos acadêmicos no programa, verificou-se que embora nervosos, os pibidianos conseguiram aplicar com segurança as aulas de revisão e a proposta de gincana do jogo da velha sobre mecânica.

Logo, diante do exposto, considera-se que a metodologia aplicada foi válida e alcançou os objetivos de revisar os conteúdos a partir do uso da gincana. Assim, a metodologia pode ser considerada proveitosa para o ensino de física, além de apresentar a possibilidade de ser adaptada para outras áreas do conhecimento. 


\section{CONCLUSÕES}

O trabalho apresentou o relato da aplicação de uma gincana baseado no jogo da velha, para revisar os assuntos sobre Leis de Newton, Trabalho e Energia. Pensou-se em utilizar a competitividade saudável entre as equipes na sala de aula para promover o trabalho em equipe, bem como o interesse dos alunos em resolver e discutir as questões que surgiam durante a gincana. Além de viabilizar um meio para os alunos de ensino médio gostarem ou se motivarem a estudar física. Verificou-se que com aulas mais dinâmicas, como a que foi apresentada, pode-se gerar bons resultados quanto à participação dos alunos. Observou-se também que a turma testou os conhecimentos sobre o assunto abordado entre os pares, aluno-aluno, de forma mais prática e num ambiente lúdico, sem o rigor de ser avaliado como numa prova, por exemplo. Ressalta-se que a gincana, sozinha, extraclasse, não resolve os problemas complexos e diversificados do Ensino de física, porém pode proporcionar momentos de discussão entre os discentes sobre as questões a serem resolvidas e o trabalho em equipe. Fatores que em conjunto podem auxiliar a tirar dúvidas e estudar o conteúdo para prova de forma mais descontraída.

Por fim, a experiência docente vivenciada pelos alunos da licenciatura em física serviu como ponto de partida para uma formação baseada em situações reais de sala de aula, fato que pode contribuir para a construção de um professor mais consciente do seu papel para exercer a profissão no futuro, preocupado com o aprendizado do aluno. E sobretudo, refletindo constantemente sobre a própria prática, buscando novas formas de aperfeiçoá-la.

\section{AGRADECIMENTOS}

À Capes - Coordenação de Aperfeiçoamento de Pessoal de Nível Superior - por financiar o Programa Institucional de Bolsa de Iniciação à Docência (PIBID) para o curso de Licenciatura em Física da Universidade Federal do Acre (UFAC).

\section{REFERÊNCIAS}

ARAUJO, E. S.; SANTOS, B. M. Jogo das grandezas: um recurso para o ensino de física. Revista do Professor de Física, v. 2, p. 73-83, 2018.

BONJORNO, J. R.; RAMOS, C. M.; PRADO, E. P.; BONJORNO, V.; BONJORNO, M. A.; CASEMIRO, R.; BONJORNO, R. F. S. A. Física: Mecânica, $1^{\circ}$ ano. São Paulo: FTD, $3^{\circ} \mathrm{Ed}, 2016$.

CARVALHO, A. M. P.; PÉREZ, D. G. Formação de Professores de Ciências: tendências e inovações. São Paulo: Cortez Editora, $9^{\circ}$ Ed, 2009. 
DARROZ, L. M.; ROSA, C. T. W.; NETO, A. F. Programa institucional de bolsas de iniciação à docência: o que apresentam os periódicos on-line. REVISTA

FORMAÇÃO@DOCENTE, Belo Horizonte, v. 10, n. 1, p. 203-212, 2018.

DURAN, Á. P. Interação social: o social, o cultural e o psicológico. Temas em

Psicologia, Ribeirão Preto, v. 1, n. 3, p. 1-8, 1993.

GERHARDT, T. E.; SILVEIRA, D. T. (org.). Métodos de pesquisa. Porto Alegre: Editora da UFRGS, 2009.

HALLIDAY, D.; RESNICK, R., WALKER, J.; Fundamentos de física, volume 1 : mecânica / tradução Ronaldo Sérgio de Biasi. Rio de Janeiro: LTC, 10 Ed, 2016.

HONORATO, C. A.; DIAS, K. K. B.; DIAS, K. C. B. APRENDIZAGEM

SIGNIFICATIVA: Uma Introdução à Teoria. Mediação, v. 13, n. 1, p. 22-37, 2018.

IMBERNÓN, F. Inovar o Ensino e a Aprendizagem na universidade. São Paulo: Cortez, 2012.

JUNIOR, E. C.; RODRIGUES, E. C.; SILVA, M. V. D.; GOMES, R. C. S.; ASSIS, C. C. B. Um estudo estatístico sobre o aproveitamento em Física de alunos de ensino médio e seus desempenhos em outras disciplinas. Revista Brasileira de Ensino de Física, v. 39, n. 1, e1403, 2017.

MENEZES, L. C.; HOSOUME, Y.; COPELLI, A. C.; TOSCANO, C.; TEIXEIRA, D. R.; SILVA, I. S.; PEREIRA, J. A.; MARTINS, J.; PIASSI, L. P. C.; PELAES, S. B.; DIAS, W. S. Leituras de Física - GREF Mecânica - para ler, pensar e fazer. Leituras de Física GREF Mecânica - para ler, pensar e fazer. São Paulo, 1998.

MOREIRA, M. A. Uma análise crítica do ensino de Física. Estudos Avançados, v. 32, n. 94, 2018.

NASCIMENTO, R. C. L. C. B.; ANTUNES, F. Educação pública de qualidade: o PIBID como uma das alternativas na formação inicial docente. RELVA, Juara/MT/Brasil, v. 2, n. 2, p. 175-185, 2015.

OLIVEIRA, H. F. A bagagem do PIBID para a formação inicial docente e para a construção da identidade profissional. Trab. Ling. Aplic. Campinas, n. 56.3, p. 913934, 2017.

PEREIRA, R. F.; FUSINATO, P. A.; NEVES, M. C. D. Desenvolvendo um jogo de tabuleiro para o ensino de física. In.: Encontro Nacional de Pesquisa em Educação em Ciências - VII Enpec, Florianópolis, 2009.

PIETROCOLA, M. A matemática como estruturante do conhecimento físico. Cad. Cat. Ens. Fís., v.19, n.1, p. 89-109, 2002. 
PUGLIESE, R. M. O trabalho do professor de Física no ensino médio: um retrato da realidade, da vontade e da necessidade nos âmbitos socioeconômico e metodológico. Ciênc. Educ., Bauru, v. 23, n. 4, p. 963-978, 2017.

RODRIGUES, M. H. S.; PINON, J. C. S.; LOPES, S. S.; ALMEIDA, A. C. P. C. Ludicidade e ensino de física: Desenvolvendo uma atividade lúdica sobre o movimento circular uniforme. Física na Escola, v. 15, n. 2, p. 52-57, 2017.

REIS, J. S.; OLIVEIRA, V. C. M.; AMORIM, A. M. A. ; SANTOS, B. M. . Ensino de termologia com aplicação do jogo "Caminhos Termométricos". Física na Escola, v. 16, p. 57-61, 2018.

SANTOS, B. M.; SOUZA, G. A. P.; PEREIRA, A. C.; PARADA, E. M. S. Formação inicial de professores de física na ufac: as contribuições e limitações do PIBID. South American Journal of Basic Education, Technical and Technological, v. 5, n. 2, 2018.

SILVA, S. M.; NUNES, C. P. O PIBID como política pública de formação de professores. Educação em Debate, Fortaleza, v. 38, n. 72, 2016.

SCHMITT, F. E.; BAMPI, F.; MACALLI, L.; KÖHNLEIN, M. M.; NICOLINI, C. A. H.; GONZATTI, S. E. M. Gincana recreativa: uma atividade para estimular o conhecimento. Revista Destaques Acadêmicos, CETEC/UNIVATES, v. 3, n. 4, 2011.

\section{APÊNDICE 1}

\section{Questões da primeira fase}

1. Seja um corpo de massa $2 \mathrm{~kg}$, em repouso, apoiado sobre um plano horizontal sob a ação das forças horizontais $\vec{F}_{1}$ e $\vec{F}_{2}$ de intensidade $10 \mathrm{~N}$ e $4 \mathrm{~N}$ respectivamente, conforme indica a figura.

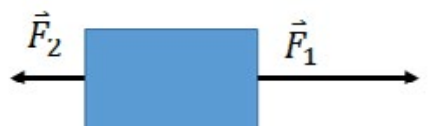

Qual a aceleração adquirida pelo corpo?
A. $3 \mathrm{~m} / \mathrm{s}^{2}$
B. $5 \mathrm{~m} / \mathrm{s}^{2}$
C. $12 \mathrm{~m} / \mathrm{s}^{2}$
D. $16 \mathrm{~m} / \mathrm{s}^{2}$
E. Nenhuma das alternativas

2. De acordo com a questão 1, achar a velocidade e o espaço percorrido pelo corpo $10 \mathrm{~s}$ após o início do movimento.
A. $120 \mathrm{~m}$
B. $180 \mathrm{~m}$
C. $150 \mathrm{~m}$
D. $140 \mathrm{~m}$
E. Nenhuma das alternativas 
3. Se a força tem o mesmo sentido do deslocamento, o trabalho é dito?
A. Nulo
B. Resistente
C. Motor
D. Trabalhoso
E. Nenhuma das alternativas

4. Se a força tem o sentido contrário do deslocamento, o trabalho é dito?
A. Nulo
B. Resistente
C. Motor
D. Trabalhoso
E. Nenhuma das alternativas

5. Se não houver deslocamento de um objeto numa certa altura o trabalho é dito?
A. Nulo
B. Motor
C. Resistente
D. Trabalhoso
E. Nenhuma das alternativas

6. O que seria força resultante?
A. Ausência de força
B. Somatório das forças
C. Uma força aplicada no corpo
D. Resistência de força
E. Nenhuma das alternativas

7. Nas provas de longa e média distância do atletismo, os corredores mantêm sua velocidade constante durante a maior parte do tempo. A partir dessa constatação, um estudante de física afirma que, durante esse tempo, os atletas não gastam energia porque a energia cinética deles não varia. Essa afirmação é:

A) verdadeira, pois os corredores se mantêm em movimento sem esforço, por inércia.

B) verdadeira do ponto de vista da física, mas falsa do ponto de vista da biologia.

C) falsa, porque a energia cinética do atleta não tem relação com o esforço muscular que ele desenvolve.

D) falsa, pois a energia cinética só se mantém constante graças ao trabalho da força muscular do atleta.

E) verdadeira, porque o trabalho da resultante das forças que atuam sobre o atleta é nulo.

8. Um garoto abandona uma pequena esfera de massa $100 \mathrm{~g}$ a $80 \mathrm{~cm}$ do solo. Após o choque, a esfera sobe chegando a uma altura máxima de $45 \mathrm{~cm}$. Supondo-se o tempo de contato da esfera com o solo igual a $0,01 \mathrm{~s}$ e a aceleração da gravidade $10 \mathrm{~m} / \mathrm{s}^{2}$, desprezando-se a resistência do ar, é correto afirmar que:

A) A quantidade de movimento da esfera foi conservada durante o choque.

B) A força média que o solo exerceu sobre a esfera foi de $10 \mathrm{~N}$. 
C) A energia mecânica do sistema Terra mais esfera foi conservada.

D) A esfera diminuiu sua energia mecânica em $0,35 \mathrm{~J}$ durante o choque.

E) O choque da esfera contra o solo foi perfeitamente elástico.

9. Quando a velocidade de um móvel duplica, sua energia cinética:
A) reduz-se um quarto do valor inicial
B) reduzir-se à metade
C) fica multiplicada por 2
D) duplica
E) quadruplica

Gabarito: 1a, 2e, 3c, 4b, 5a, 6b, 7d ,8d, 9e

\section{Questões da segunda fase}

1) Assinale a alternativa que contém um exemplo de aplicação da Primeira Lei de Newton.

A. Um livro apoiado sobre uma mesa horizontal é empurrado horizontalmente para a direita com uma força de mesma intensidade da força de atrito que atua sobre ele, mantendo-o em movimento retilíneo e uniforme.

B. Quando um tenista acerta uma bola com sua raquete, exerce nela uma força de mesma direção e intensidade da que a bola exerce na raquete, mas de sentido oposto.

C. Em uma colisão entre duas bolas de bilhar, a quantidade de movimento do sistema formado por elas imediatamente depois da colisão é igual à quantidade de movimento do sistema imediatamente antes da colisão.

D. Em um sistema de corpos onde forças não conservativas não realizam trabalho, só pode ocorrer transformação de energia potencial em cinética ou de energia cinética em potencial.

E. Se a força resultante que atua sobre um carrinho de supermercado enquanto ele se move tiver sua intensidade dobrada, a aceleração imposta a ele também terá sua intensidade dobrada.

2) Marque a alternativa correta a respeito da Terceira lei de Newton.

A. A força normal é a reação da força peso.

B. Ação e reação são pares de forças com sentidos iguais e direções opostas.

C. A força de ação é sempre maior que a reação.

D. Toda ação corresponde a uma reação de mesma intensidade e sentido.

E. Toda ação corresponde a uma reação de mesma intensidade, mas sentido oposto.

3) Marque a alternativa incorreta a respeito da Leis de Newton.

A. De acordo com a Terceira Lei de Newton, peso e normal não podem ser um par de ação e reação.

B. Para velocidades próximas à velocidade da luz, a mecânica newtoniana deve ser substituída pela Teoria da Relatividade de Einstein.

C. A Segunda Lei de Newton diz que a força resultante que atua sobre um objeto é igual à razão da variação da quantidade de movimento pela variação do tempo.

D. A massa é a medida quantitativa da inércia. 
E. As Leis de Newton são válidas para qualquer referencial.

4) Marque a alternativa correta a respeito da Terceira Lei de Newton.

A. Peso e normal, por atuarem no mesmo corpo, não são um par de ação e reação.

B. A força normal é a reação da força peso.

C. De acordo com a Terceira Lei de Newton, ação e reação são forças que atuam em um mesmo corpo.

D. Ação e reação atuam em corpos diferentes, assim como a força peso e a normal.

E. Todas as afirmações anteriores estão incorretas.

5) A respeito do conceito da inércia, assinale a frase correta:

A. Um ponto material tende a manter sua aceleração por inércia.

B. Uma partícula pode ter movimento circular e uniforme, por inércia.

C. O único estado cinemático que pode ser mantido por inércia é o repouso.

D. Não pode existir movimento perpétuo, sem a presença de uma força.

E. A velocidade vetorial de uma partícula tende a se manter por inércia; a força é usada para alterar a velocidade e não para mantê-la.

6) O Princípio da Inércia afirma:

A. Todo ponto material isolado ou está em repouso ou em movimento retilíneo em relação a qualquer referencial.

B. Todo ponto material isolado ou está em repouso ou em movimento retilíneo e uniforme em relação a qualquer referencial.

C. Existem referenciais privilegiados em relação aos quais todo ponto material isolado tem velocidade vetorial nula.

D. Existem referenciais privilegiados em relação aos quais todo ponto material isolado tem velocidade vetorial constante.

E. Existem referenciais privilegiados em relação aos quais todo ponto material isolado tem velocidade escalar nula.

7) As estatísticas indicam que o uso do cinto de segurança deve ser obrigatório para prevenir lesões mais graves em motoristas e passageiros no caso de acidentes. Fisicamente, a função do cinto está relacionada com a:

A. Primeira Lei de Newton;

B. Lei de Snell;

C. Lei de Ampère;

D. Lei de Ohm;

E. Primeira Lei de Kepler.

8) Uma folha de papel está sobre a mesa do professor. Sobre ela está um apagador. Dando-se, com violência, um puxão horizontal na folha de papel, está se movimenta e o apagador fica sobre a mesa. Uma explicação aceitável para a ocorrência é:

A. Nenhuma força atuou sobre o apagador;

B. A resistência do ar impediu o movimento do apagador;

C. A força de atrito entre o apagador e o papel só atua em movimentos lentos;

D. A força de atrito entre o papel e a mesa é muito intensa;

E. A força de atrito entre o apagador e o papel provoca, no apagador, uma aceleração muito inferior à da folha de papel. 
9) Um ônibus percorre um trecho de estrada retilínea horizontal com aceleração constante. No interior do ônibus há uma pedra suspensa por um fio ideal preso ao teto. Um passageiro observa esse fio e verifica que ele não está mais na vertical. Com relação a este fato podemos afirmar que:

b) O peso é a única força que age sobre a pedra.

c) Se a massa da pedra fosse maior, a inclinação do fio seria menor.

d) Pela inclinação do fio podemos determinar a velocidade do ônibus.

e) Se a velocidade do ônibus fosse constante, o fio estaria na vertical.

f) A força transmitida pelo fio ao teto é menor que o peso do corpo.

Gabarito: 1a, 2e, 3e, 4a, 5e, 6a, 7a, 8e, 9d 